\title{
SIMULATION OF THE TEMPERATURE PROFILE OF A PECTIN SOLUTION IN A PLATE HEAT EXCHANGER: A NON-LINEAR SYSTEM APPROACH FOR CONTROL
}

\author{
M. R. Scariot ${ }^{\mathrm{a}}$, ABSTRACT \\ M. I. Berto ${ }^{b}$, \\ and V. Silveira ${ }^{c}$

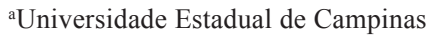 \\ Faculdade de Engenharia de Alimentos \\ Departamento de Engenharia de Alimentos \\ CP. 6121, Campinas, SP, Brasil \\ marlei@fea.unicamp.br \\ ${ }^{\mathrm{b}}$ Instituto de Tecnologia de Alimentos \\ C.P 139, Campinas, SP, Brasil \\ miberto@ig.com.br \\ cvivaldo@fea.unicamp.br \\ Experimental measurement can be made only of inlet and outlet global temperature of \\ plate heat exchanger (PHE), therefore the temperature profile along of a PHE is hardly \\ ever known. The goal of this work was to evaluate the influence of a non-Newtonian \\ behavior of pectin solution in the temperature response curves along of the PHE. The \\ results were obtained using a simulation codified in Matlab 6.1 software. The response \\ curves resulted from the simulations were fitted to models for identification and \\ characterization of the system linearity. The result shows a clear non-linear behavior of \\ the response curves along the PHE. \\ Keywords: plate heat exchanger; simulation; pectin; control.
}

\section{NOMENCLATURE}

I rate flow product disturbance, $45.5 \mathrm{~kg} / \mathrm{h}$

j number of channels

$\mathrm{k}$ number of channels subdivisions

$\mathrm{K}$ consistency coefficient, dimensionless

$\mathrm{Kp} \quad$ static gain parameter, ${ }^{\circ} \mathrm{C} \cdot \mathrm{h} / \mathrm{kg}$

$\mathrm{n} \quad$ flow behavior index, dimensionless

$\mathrm{R}^{2} \quad$ coefficient of determination, dimensionless

$\mathrm{t}$ time, $\min$

$\mathrm{T}$ temperature, ${ }^{\circ} \mathrm{C}$

$\mathrm{X}$ pectin concentration, (w/w)

\section{Greek symbols}

$\tau \quad$ time constant, $\min$

$\delta \mathrm{t} \quad \mathrm{t}-\mathrm{t}_{1^{\circ} \mathrm{rp}}, \min$

$\delta \mathrm{T} \quad \mathrm{T}-\mathrm{T}_{1^{\circ} \mathrm{rp}},{ }^{\circ} \mathrm{C}$

$\zeta \quad$ damping factor, dimensionless

\section{Subscripts}

$1^{\circ} \mathrm{rp}$ first steady state

\section{INTRODUCTION}

Considering the fact that most fluid food presents a non linear behavior, the knowledge of the internal dynamic behavior and the identification of the control parameters along the channels of the plate heat exchanger (PHE) are essential because it allows visualization and better understanding of the control process.

Many studies were carried out addressing transient shell and tube heat exchanger, whereas only a few investigations are found for PHE, e.g. a simulation of a transient response of a multipass PHE developed by Das and Murugesan (2000) and an experimental and analytic study of a PHE by Masubuchi and Ito (1977).

Some problems arise when carrying out experimental tests in PHE. One of them is that it is only possible to measure the inlet and outlet global temperatures and therefore the temperature profile along the PHE is hardly ever known (Rene et al., 1991).

From a process point of view, the working fluids in a food industry are very complex and the knowledge of temperature profile along the PHE is very important, since it allows the evaluation of the effect of a specific local temperature in changes of the physical and rheological properties and in the process quality of fluid food. Excessive heating, even for a short time, can affect food quality and its nutritious properties.

The scope of this work was to study the behavior of the temperature response curves of the product along the PHE and to find the best control parameters by mean of fitting models. Modeling and simulation of a PHE were used as the base for all these studies. The modeling considers the 
influence of the rheological properties. The flow behavior index and the consistency index are assumed dependent on the temperature and fluid concentration. Rheological empiric models were used in the simulation of the pectin solution heat process.

The response curves were obtained after disturbance in the product flow rate. Different models were evaluated to identify the dynamic behavior of the control parameters along the PHE.

\section{EXPERIMENTS}

The PHE dynamic simulator was codified by Berto and Silveira (2003) and the mathematical modeling was based on the assumptions of Sharifi et al. (1995) and Rene et al. (1991). The model describes a transient process from energy balance equations and uses the finite difference method for the numerical calculations of the fluid temperature.

The temperature profile along the PHE was evaluated for a pectin solution $2 \%(\mathrm{w} / \mathrm{w})$. The rheological properties of the pectin solution were experimentally measured by Marcotte et al. (2001) and the pectin solution was described by power law.

The values of the consistency coefficient $(\mathrm{K})$ and the flow behavior index (n) were fitted to a fluid concentration (X) and temperature (T) dependent function, showed in Eqs. (1) and (2). The adjustment was carried out using the software STATISTIC 5.0 and the Quasi-Newton parameter estimation method.

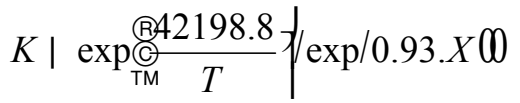

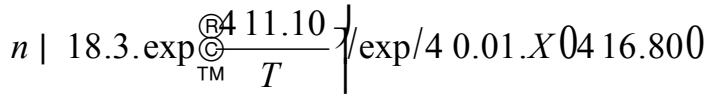

Figure 1 shows a representation of the PHE used in the simulation. The PHE presents eight channels, which are subdivided into six equal parts $(\mathrm{k})$.

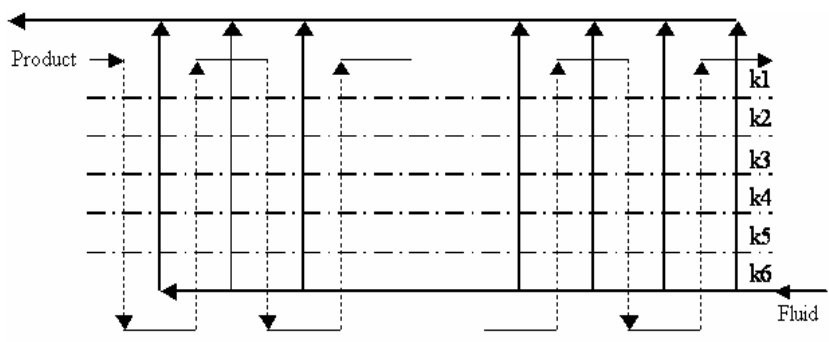

Figure 1. Plate heat exchanger representation.

The initial operation conditions of the PHE are presented in Tab. 1.

Table 1. Operational conditions of the PHE.

\begin{tabular}{|c|c|}
\hline Variables & $\begin{array}{c}\text { Operational } \\
\text { conditions }\end{array}$ \\
\hline Pectin solution inlet temperature $\left({ }^{\circ} \mathrm{C}\right)$ & 25 \\
\hline Hot fluid (water) inlet temperature $\left({ }^{\circ} \mathrm{C}\right)$ & 80 \\
\hline Pectin solution flow rate $(\mathrm{L} / \mathrm{h})$ & 400 \\
\hline Water flow rate $(\mathrm{L} / \mathrm{h})$ & 2400 \\
\hline Pectin solution passes & 8 \\
\hline Hot fluid (water) passes & 1 \\
\hline
\end{tabular}

In order to evaluate the behavior of the heat exchange by the temperature profile in each channel subdivision along a PHE, a step disturbance of $45.5 \mathrm{~L} / \mathrm{h}$ was imposed to the system rate flow, in the pectin solution flow rate.

The temperature response curves of the product were fitted to different linear equations as: first order equation, first order with dead time, and second order equation. For the adjustment of the second order equation, the best case for the damping factor between $0,8<\zeta<1,2$ and $\zeta=1$ was evaluated.

The parameters of the equations were obtained by means of a non-linear data fitting using a Newton-Gauss Method, available in the software Matlab 6.1. The parameters were obtained for all channels (j) and channels subdivisions (k).

Figures 3-6 were plotted to verify the linearity of the product temperature in different positions of the PHE (channels 1, 3, 5 and 7), which show the behavior of the response curves. Each channel presents six temperature profiles that correspond to the subdivision of the channels $(\mathrm{k})$. 


\section{RESULTS AND DISCUSSION}

\section{Model Fitting for Identification of the Dynamic System Behavior}

The temperature response curves of the product, obtained by means of the process simulation, presents form of ' $\mathrm{S}$ '. Figure 2 shows the adjustments that were carried out for the response curves in the PHE outlet.

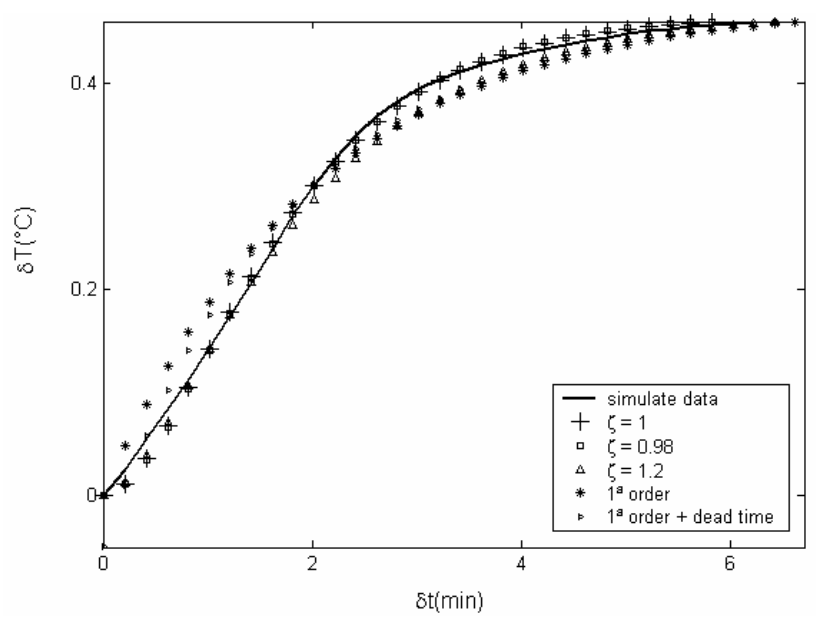

Figure 2. Adjustments of the temperature response curve of the outlet product after step disturbance.

Once all the response curves of the process were best fitted $\left(\mathrm{R}^{2}>0.9\right)$ by the second order equation with the damping factor $(\zeta=1)$, this behavior was considered representative of the process.

The parameters $\tau$ e Kp were fitted to the second order model with $\zeta=1$, as shown by Eq. (3):

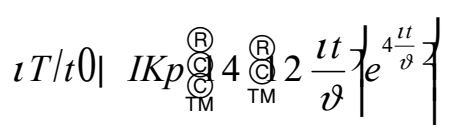

\section{Response curves}

Figures 3-6 present the response curve for each channel and was obtained by the ratio between the temperature difference and the disturbance value versus the time difference.

The temperature profile of the pectin solution $2 \%(\mathrm{w} / \mathrm{w})$ of concentration, for the four product channels $(1,3,5$ e 7$)$ are showed in Figs. $3-6$, where is can be seen that each channel presents a transient behavior of the product temperature in each channel subdivision (k) in six different response curves ( $\mathrm{k} 1$ to $\mathrm{k} 6$ ), in the direction of the product flow rate. It is important to observe the direction of the product path as showed in Fig. 1.

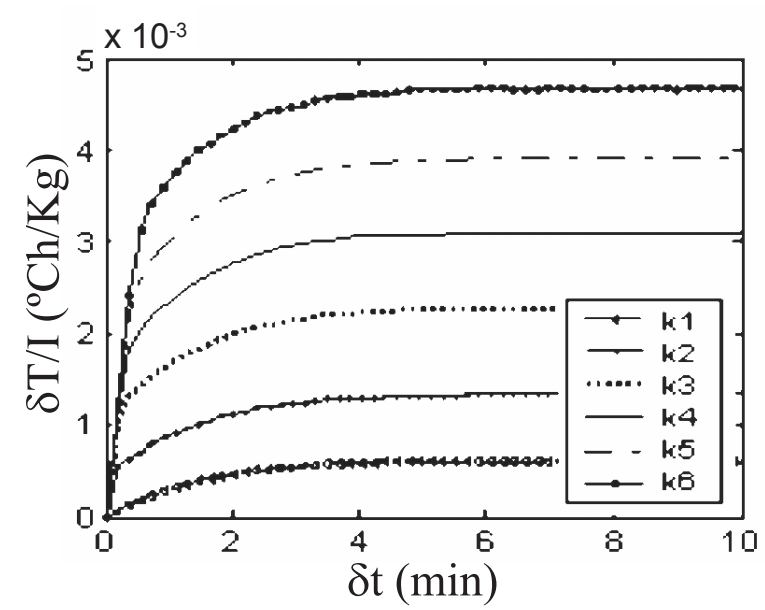

Figure 3. Temperature response curves of the product for channel 1 after step disturbance in the pectin flow rate.

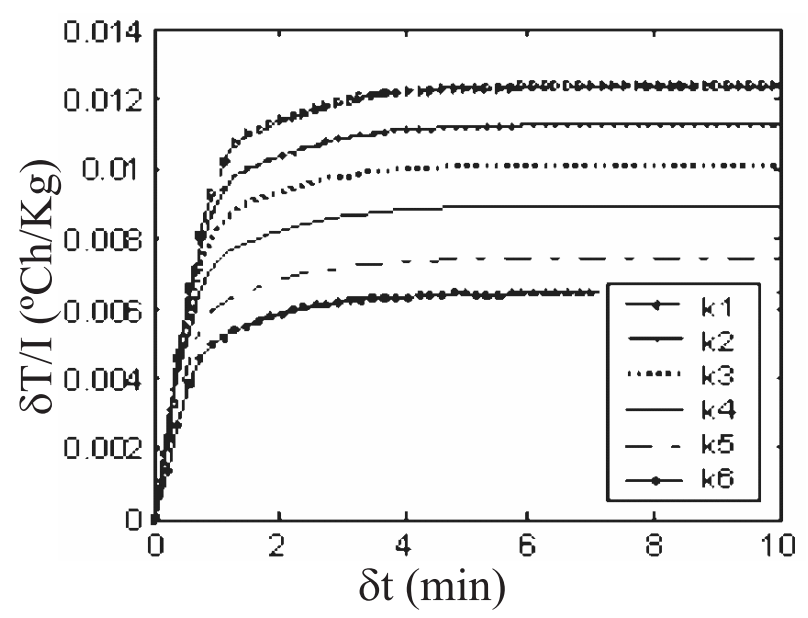

Figure 4. Temperature response curves of the product for channel 3 after step disturbance in the pectin flow rate.

Evaluating Tabs. 2 and 3 and Figs. $3-6$ it is possible to verify the growth of the static gain parameter $\mathrm{Kp}$ along the PHE, along the channel and in its subdivisions, showing the increase of the static gain parameter. 


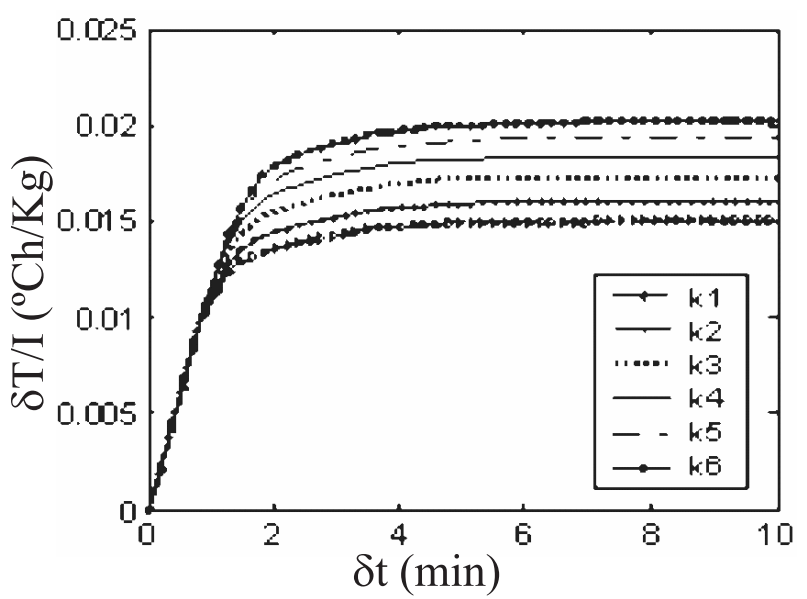

Figure 5. Temperature response curves of the product for channel 5 after step disturbance in the pectin flow rate.

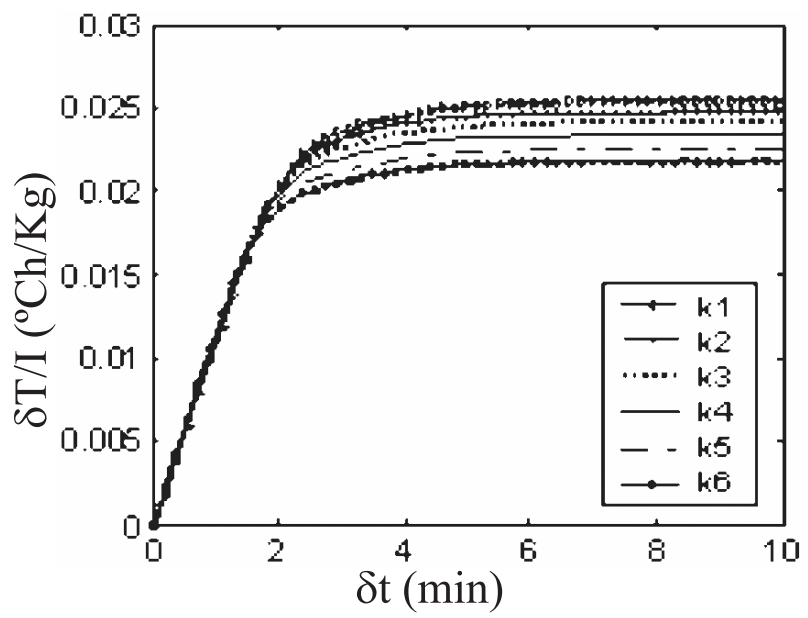

Figure 6. Temperature response curves of the product for channel 7 after step disturbance in the pectin flow rate.

Table 2. Parameter Kp fitted in each channel (j) and channel subdivisions $(\mathrm{k})$.

\begin{tabular}{ccccc}
\hline Kp & Channel 1 & Channel 3 & Channel 5 & Channel 7 \\
\hline k1 & 0.0006 & 0.0122 & 0.0148 & 0.0253 \\
k2 & 0.0013 & 0.0111 & 0.0158 & 0.0247 \\
k3 & 0.0022 & 0.0100 & 0.0171 & 0.0240 \\
k4 & 0.0030 & 0.0088 & 0.0182 & 0.0233 \\
k5 & 0.0038 & 0.0073 & 0.0192 & 0.0223 \\
k6 & 0.0046 & 0.0063 & 0.0200 & 0.0216 \\
\hline
\end{tabular}

Table 2 shows that the static gain parameter Kp presents a constant growth with channel direction as channel subdivision, in the path of the product flow. The direction of the product flow is indicated in Tabs. 2 and 3.

Table 3. Parameter $\tau$ fitted in each channel (j) and channel subdivisions $(\mathrm{k})$.

\begin{tabular}{cc|ccc}
\hline Kp & Channel 1 & Channel 3 & Channel 5 & Channel 7 \\
\hline k1 & 0.0006 & 0.0122 & 0.0148 & 0.0253 \\
k2 & 0.0013 & 0.0111 & 0.0158 & 0.0247 \\
k3 & 0.0022 & 0.0100 & 0.0171 & 0.0240 \\
k4 & 0.0030 & 0.0088 & 0.0182 & 0.0233 \\
k5 & 0.0038 & 0.0073 & 0.0192 & 0.0223 \\
k6 & 0.0046 & 0.0063 & 0.0200 & 0.0216 \\
\hline
\end{tabular}

The evaluation of the behavior along the PHE can be helped by observing Tab. 3, where the time constant shows a tendency of growth after the first channel, therefore the product requires more time to reach the steady state.

\section{CONCLUSIONS}

Through the temperature profile along the PHE it is possible to know the dynamic behavior of the system and to verify the strong non-linearity of the parameters $\mathrm{Kp}$ and $\tau$ with relation of the channels and its subdivisions.

For each point along the PHE, there are different values for the second order model parameters, and this transient behavior indicates the need of tuning the controller to take into account these non-linearities of the process.

The knowledge of the behavior of the product along the PHE and the use of an adequate tuning is crucial in the food industry process. This study is fundamental in product quality control, since the use of an inadequate tuning, that does not consider the non-linearities of the process, can have a negative influence on food safety and on the sensorial qualities of the final product. 


\section{ACKNOWLEDGEMENTS}

The authors acknowledge with gratitude the National Council for Scientific and Technological Development (CNPQ) for supporting the research.

\section{REFERENCES}

Berto, M. I., Silveira, V., 2003, Dynamic analysis of the cooling process in plate heat exchangers, Journal of Food Process Engineering, Vol. 26, No. 6, pp. 499-513.

Das, S. K., Murugesan, K., 2000, Transient response of multipass plate heat exchangers with axial thermal dispersion in Fluid, International Journal of Heat and Mass Transfer, Vol. 43, pp. 4327-4345.

Marcotte, M. L., Hoshahili, A. R. T., Ramaswamy, H. S., 2001, Rheological properties of selected hydrocolloids as a function of concentration and temperature, Food Research International, Vol. 34, pp. 695-703.

Masubuchi, M., Ito, A., 1977, Dynamic analysis of plate heat exchanger system, Bulletin of the JSME, No. 142, pp. 20.

Rene, F., Leuliet, J. C., Lalande, M., 1991, Heat Transfer to Newtonian and non-Newtonian food fluids in Plate Heat Exchangers. Trans. Chemical Engineering, Vol. 69-C, pp. 115-126.

Sharifi, F., Narandkji, G., Mehravaran, K., 1995, Dynamic Simulation of Plate Heat Exchangers, International Journal of Heat and Mass Transfer, Vol. 22, pp. 213-225. 